\title{
CORRESPONDENCE
}

\section{Is pulmonary arterial impedance affected by breathing?}

\section{To the Editor:}

In their editorial on the clinical significance of pulmonary arterial input impedance, GRANT and LIEBER [1], raise the question of whether pulmonary impedance is affected by breathing. With reference to our paper published in the same issue of the European Respiratory Journal [2], they wrote "CASTIGLIONI et al. found no significant changes of impedance during the respiratory cycle".

We are quite surprised in reading this statement. In fact, the results of our study lead to the opposite conclusion. Indeed, we demonstrated that input impedance does change during the respiratory cycle in spontaneously breathing animals, as is stated both in the abstract ("Therefore, spontaneous respiration was shown to influence input impedance significantly") and in the discussion of our paper.

To our knowledge, this is the first time that spontaneous respiration was shown to influence input impedance. As emphasized in the discussion, we obtained this result because impedance was measured at three specific points in the respiratory cycle, inspiration, expiration and postexpiration; and impedances measured during inspiration and expiration were compared to impedance measured during postexpiration (in fact, previous studies $[3,4]$ did not find any difference by simply com- paring inspiration to expiration). Thus, it is difficult to understand why Grant and Lieber [1] state that we did not find any significant difference - we actually did find it! - because in our study "impedance was measured only at three specific points in the respiratory cycle".

\section{References}

1. Grant BJB, Lieber BB. Clinical significance of pulmonary arterial input impedance. Eur Respir J 1996; 9: 2196-2199.

2. Castiglioni P, Di Rienzo M, Grossoni M, Tommasini R, Morpurgo M. Does spontaneous respiration alter pulmonary artery input impedance? Eur Respir J 1996; 9: 2328-2334.

3. Murgo JF, Westerhof N. Input impedance in the pulmonary arterial system in normal man: effects of respiration and comparison to systemic impedance. Circ Res 1984; 54: 666-673.

4. Wieland JM, Kussmaul WY, Parker HG, Laskey WK. Effects of respiration on pulmonary artery input impedance. (Abstract). Clin Res 1986; 34: 865A.

\section{P. Castiglioni, M. Di Rienzo, M. Morpurgo}

LaRC, Centro di Bioingegneria, via Gozzadini 7, I-20148 Milano, Italy.

\section{REPLY}

\section{From the authors:}

The authors quoted from our editorial [1] out of context. They omitted the words of the offending sentence: "In contrast,...". We were contrasting their results [2], which found no difference in pulmonary arterial input impedance between inspiration and expiration, with our results which did show a difference in impedance measured at the start of inspiration and the start of expiration [3]. We did not intend to imply that they found no difference in impedance between the pause in the respiratory cycle, with impedance measured during inspiration or expiration. It was not our intent to rewrite their results which stand as written, but there are differences in interpretation which perhaps should have been stated more explicitly.

In the discussion [2], the authors indicated that the lack of difference in pulmonary arterial input impedance between inspiration and expiration was because their measurements were conducted at the same lung volume during inspiration and during expiration. This line of reasoning implies that the difference in imped- ance measured during the pause in the respiratory cycle at the end of expiration and the impedance measured during inspiration or during expiration is related to differences in lung volume. The authors did not provide any measurements to support their claim that this difference in lung volume could explain the alterations in impedance. We have shown previously that the changes in pulmonary arterial input impedance during the respiratory cycle were independent of the changes of lung volume produced by altering the level of positive endexpiratory pressure [3]. Since their explanation of their inability to observe a difference between inspiration and expiration seemed unlikely, we sought to provide alternatives.

It is important to provide a plausible mechanism because the pattern of their results renders it difficult to determine whether the differences in impedance that they observed during the respiratory cycle were due to variations of the respiratory cycle, or simply artefactual. Measurements made during the respiratory pause were obtained when there was no change in transpulmonary pressure. The measurements made during inspiration and expiration were made during dynamic changes of transpulmonary pressure. While their correction for leakage may reduce these artefacts, there is no 
convincing evidence presented that this process eliminated the problem. It was for this reason that we proceeded to develop alternative approaches to resolve this issue $[4,5]$.

Despite these subtle differences in interpretation, we seem to agree that the two sets of experimental results are not discordant. We thank the authors for drawing this matter to our attention and providing us with the opportunity to rectify any misunderstanding.

\section{References}

1. Grant BJB, Lieber BB. Clinical significance of pulmonary arterial input impedance. Eur Respir $J$ 1996; 9: 2196-2199.

2. Castiglioni P, DiRienzo M, Grossoni M, Tommasini R,
Morpurgo M. Does spontaneous respiration alter pulmonary artery input impedance? Eur Respir J 1996; 9: 2328-2334.

3. Grant BJB, Fitzpatrick JM, Lieber BB. Time-varying pulmonary arterial compliance. J Appl Physiol 1991; 70: 575-583.

4. Lieber BB, Li Z, Grant BJB. Beat-by-beat changes of viscoelastic and inertial properties of the pulmonary arteries. J Appl Physiol 1994; 76: 2348-2355.

5. Li Z, Grant BJB, Lieber BB. Time-varying pulmonary arterial input impedance via wavelet decomposition. $J$ Appl Physiol 1995; 78: 2309-2319.

\section{B.J.B. Grant, B.B. Lieber}

Depts of Medicine and of Aerospace and Mechanical Engineering, State University of New York at Buffalo, Buffalo, NY, USA. 